\title{
Diferencias culturales y métodos de enseñanza de lenguas
}

\author{
Cultural differences and language teaching methods \\ Áurea Lilian García Escalona ${ }^{a}$
}

\begin{abstract}
:
The disciplinary field of language teaching creates theoretical proposals that result in curricular projects implemented at an institutional level, and sometimes in national magnitudes. In this paper, it is noted that Chinese teachers are not necessarily governed by the disciplinary theoretical notions that construct the curricular proposals, but rather hold educational conceptions related to the cultural system of which they are part. This paper proposes to pay attention to the teachers' ideas about learning and teaching, the influence these ideas have on the execution of language teaching methods, and the processes that continually emerge in the classroom. Likewise, it proposes the need to use transdisciplinary and complex approaches in the creation of curricular proposals.
\end{abstract}

\section{Keywords:}

Language teaching, communicative approach, semiotic-discursive practices, transdisciplinarity

\section{Resumen:}

Desde el campo disciplinar de la enseñanza de lenguas, surgen propuestas teóricas que se ven traducidas en proyectos curriculares que se buscan implementar a un nivel institucional y, en ocasiones, en magnitudes nacionales. Se observa que los docentes (en este caso, de origen chino) no necesariamente se rigen por las nociones teóricas que construyen las propuestas curriculares y que, más bien, sostienen nociones educativas características del sistema cultural del cual forman parte. Este trabajo propone dar cuenta de la importancia que tienen las nociones de los docentes acerca de los actos de aprender y de enseñar en la ejecución de métodos de enseñanza de lenguas y los procesos que emergen en el aula, así como en la necesidad de emplear enfoques transdisciplinarios y complejos en la creación de propuestas curriculares.

\section{Palabras Clave:}

Enseñanza de lenguas, enfoque comunicativo, prácticas semiótico-discursivas, transdisciplinariedad

\section{Introducción}

El campo de enseñanza de lenguas ha tenido un recorrido singular que se ha visto enmarcado por el devenir de las disciplinas con las que se relaciona, tales como la Lingüística, la Pedagogía, la Psicología, la Sociología, entre otras. La constante renovación de teorías provenientes de otras disciplinas, ha influido en los nuevos aportes provenientes del campo de la educación lingüística, hecho que se ha podido ver reflejado en las reformas aplicadas a los currículos de lenguas.

La ejecución de dichas reformas curriculares se ha enfrentado con muchos desafíos que tienen que ver, sobre todo, con la falta de apego, por parte de los actores relacionados, a las propuestas realizadas por las nuevas teorías disciplinares y que no pocos autores han querido adjudicar a la falta de capacitación docente y a la poca claridad con la que las instituciones educativas se han manejado en su ejecución.

En este trabajo se pone atención en las nociones que los diferentes actores tienen tanto en las acciones de enseñar y de aprender como de los roles que cada uno cumple. Se propone analizar dichas concepciones a partir del contexto cultural del cual proceden. Asimismo, con base en la observación de la labor del docente y de los métodos de enseñanza de lenguas, se analiza la función de las prácticas semiótico-discursivas de las cuales son parte y que se desenvuelven en el aula.

Esto nos podría llevar a plantear respuestas diferentes acerca de la causa de la falla de implementación de enfoques provenientes del ámbito disciplinar en

${ }^{a}$ Autor de Correspondencia, Universidad Nacional Autónoma de México, https://orcid.org/0000-0002-7705-5400 
currículos de lenguas, cuyos sistemas culturales difieren de los espacios semióticos que generan dichos saberes disciplinares. Se considera que esta revisión nos podría llevar a plantear la necesidad de hacer caso a saberes externos al ámbito disciplinar, con la finalidad de crear propuestas curriculares que permitan dar voz a los diferentes actores y que verdaderamente funcionen.

\section{La enseñanza de lenguas y el diseño curricular: el impacto del enfoque comunicativo}

Alrededor de los años 70 del siglo pasado, en el campo de la Lingüística comenzó a aparecer un cambio de atención hacia el estudio del uso de la lengua en los actos comunicativos de las personas. Dicho cambio de enfoque se vio reflejado en el auge de disciplinas tales como: la pragmática, la sociolingüística, la psicolingüística, el análisis del discurso, etcétera, que proponían un enfoque más social del estudio de las lenguas y una aproximación al uso del lenguaje como es usado en la vida diaria.

En el campo de la Lingüística, este nuevo enfoque es considerado portador de una visión intermedia entre las propuestas antecedentes del empirismo y el mentalismo. El primero de ellos busca datos observables para el estudio de la lengua, y se ve traducido en una lingüística estructural, la cual, con la finalidad de estudiar las lenguas, recurre "al procedimiento de utilizar ejemplos reales de habla (parole) como punto de partida para el análisis" (Johnson, 2008: 76). El mentalismo plantea que, para poder comprender aspectos importantes acerca de la lengua, el estudio de ésta no se puede limitar a lo observable, y se ve reflejado en una lingüística transformacional, la cual, al dar cuenta de otro nivel de análisis oracional (estructura profunda), considera que "las verdades no observadas son importantes para comprender cómo funciona la langue" (Johnson, 2008: 83). Mientras que la sociolingüística, parte del entendimiento de que la lengua no es sólo gramática y sintaxis, sino también -y sobre todo-una multiplicidad de actos de habla entre personas.

A esta capacidad de hacer unas y otras cosas con las palabras se le ha atribuido el nombre de competencia comunicativa $y$, en comparación de la competencia lingüística, que atiende los aspectos gramaticales de una lengua, ésta se enfoca en lo que un hablante necesita para comunicarse de manera eficaz bajo ciertos contextos dados. Lomas utiliza la definición que Gumperz y Hymes (1972: vii) ofrecen de la competencia comunicativa en "Directions of sociolinguistics. The ethnography of communication":

[...] mientras los estudiosos de la competencia lingüística intentan explicar los aspectos de la gramática que se creen comunes a todos los seres humanos independientemente de los determinantes sociales, los estudiosos de la competencia comunicativa tratan a los hablantes como miembros de unas comunidades que desempeñan ciertos papeles y tratan de explicar su uso lingüístico para autoidentificarse y para guiar sus actividades (Lomas 2014: 44).

Todas estas nuevas ideas, provenientes del campo de la Lingüística acerca de cómo es que se entiende el lenguaje, han incidido en el campo de enseñanza de idiomas, al generar una perspectiva más comunicativa de los procesos de aprendizaje y de enseñanza. Este cambio ha promovido el surgimiento de enfoques que proponen atender no sólo el aspecto estructural de la lengua, sino también las funciones comunicativas que ésta cumple, es decir, lo que se puede hacer con dichos elementos en un acto comunicativo.

La educación lingüística se preocupará ahora no sólo por transmitir un conocimiento gramatical, sino también por contribuir al desarrollo de una competencia comunicativa en las personas a través del aprendizaje de destrezas usuales en la vida diaria, tales como hablar, leer, escuchar y escribir. Acerca de este enfoque comunicativo y de su impacto en el aprendizaje y enseñanza de lenguas, Littlewood menciona:

Un enfoque comunicativo abre una perspectiva más amplia sobre el aprendizaje de lenguas. En concreto, nos hace ser más conscientes de que no basta con enseñar a los estudiantes cómo manipular las estructuras de la lengua extranjera. También han de desarrollar estrategias para relacionar esas estructuras con sus funciones comunicativas en situaciones y tiempo reales. Por consiguiente, debemos proporcionar a los estudiantes oportunidades variadas para que usen la lengua por sí mismos con finalidades comunicativas (Littlewood, 1996: 15).

A su vez, este énfasis comunicativo de la educación lingüística ha influido, en mayor o menor medida, en la reforma de programas de enseñanza de lenguas (tanto de segundas lenguas, como de lenguas extranjeras y de lenguas maternas), en los que se ha buscado orientar la enseñanza del lenguaje hacia el aprendizaje de conocimientos, habilidades, estrategias y actitudes que contribuyan a la adquisición y desarrollo de una competencia comunicativa en las personas.

Lomas (2014) hace una distinción entre los enfoques que han dominado la escena en el campo del diseño de programas de enseñanza de lenguas, en especial, de segundas lenguas. Menciona, por un lado, los enfoques formales que, guiados por una lista de estructuras gramaticales, se preocupan por promover una competencia gramatical y una corrección lingüística; los enfoques funcionales que, dirigidos a dominar los usos o funciones de la lengua, sustituyen dicha lista de estructuras gramaticales por una de uso de la lengua en determinados actos de habla, tales como: saludar, pedir información, entre otras. Menciona, también, que los enfoques procesuales, que estarán dirigidos a promover 
de manera integral el aprendizaje de conocimientos, habilidades, estrategias y actitudes que favorezcan el desarrollo de una competencia comunicativa, tendrán la siguiente función:

Mientras los programas formales se orientan a fomentar el conocimiento formal de la lengua y de sus reglas internas $(y$, por tanto, la competencia gramatical y la corrección lingüística) y los programas funcionales-en sintonía con la filosofía del lenguaje y con la teoría de los actos de habla - se dirigen al dominio de las funciones del lenguaje y a la identificación de las intenciones comunicativas de los hablantes ( $y$, por tanto, a una actuación comunicativa eficaz), los programas procesuales (como los programas de aprendizaje por tareas o los programas comunicativos) se caracterizan por tener como objetivo esencial el desarrollo de la competencia comunicativa del alumnado, por integrar en un único proceso el conocimiento lingüístico-discursivo y metacognitivo del lenguaje, por poner un especial énfasis en las habilidades y destrezas del uso lingüístico en torno a tareas comunicativas y por adoptar una perspectiva cognitiva (Lomas, 2014: 56).

La influencia que el enfoque comunicativo ha tenido en el campo del diseño de programas -y que se traduce en estos enfoques procesuales mencionados por Lomasha provocado la necesidad de renovación curricular en muchas instituciones encargadas de la enseñanza de lenguas. En Latinoamérica, la aplicación de enfoques comunicativos al ámbito curricular ha sido palpable a partir de los años noventa y hay que decir que su implementación se ha enfrentado con no pocas dificultades.

De acuerdo con Díaz, Gracida y Sule (en Lomas, 2014), a partir de 1993, en México se comenzó a tomar el enfoque comunicativo, como estandarte para la enseñanza de español como lengua materna, así como para la enseñanza de segundas lenguas: "se realizó toda una modificación a programas de estudio, libros de texto y formación de profesores, tomando en consideración los nuevos aportes lingüísticos que dejaron de estar centrados en las estructuras oracionales y ampliaban la perspectiva hacia el trabajo con ellas, las funciones del lenguaje y las situaciones comunicativas, así como, los nuevos aportes que se daba al aprendizaje desde el constructivismo, la psicolongüística y la sociolingüística" (Lomas, 2014: 178).

Sin embargo, como en toda reforma educativa, surgió, en los primeros años de dichas modificaciones, un caos relacionado con los aspectos teóricos y prácticos del nuevo enfoque, el cual, según dichas autoras, se debió no sólo a factores políticos, sindicales y sociales, sino sobre todo, a la falta de capacitación docente y la falta de claridad por parte de las autoridades educativas para dar a conocer en qué consistía dicho enfoque, lo cual derivó en grandes distorsiones del enfoque, que iban desde pensar que éste proponía eliminar de lleno la gramática del proceso de enseñanza hasta apoyar su utilización en la enseñanza de otras áreas, tales como las matemáticas (Lomas, 2014).

La opinión de Lomas. acerca de la causa de la falla de implementación del enfoque comunicativo en los programas latinoamericanos, es diferente: no apunta a que sea una falta de capacitación por parte de las autoridades educativas la que no haya permitido un óptimo desempeño del enfoque comunicativo en las aulas; plantea, más bien, que existe un abismo entre los deseos de impulsar una didáctica comunicativa de la lengua y lo que ocurre en realidad en las aulas, cuyo desconocimiento genera incertidumbre y dificultades que hacen preciso preguntarse en qué consiste éste, es decir, qué es eso que se encuentra entre la teoría y la práctica:

De ahí que, al cabo de casi tres décadas de currículos lingüísticos de orientación comunicativa y de una innegable influencia de los enfoques pragmáticos, textuales y discursivos en los estudios del lenguaje, convenga preguntarse por lo que sucede más allá de las disposiciones legales y de la investigación didáctica, es decir, por la coherencia (e incoherencia) entre lo que se enuncia en la teoría y lo que sucede en la práctica, entre lo que se dice que se debe hacer y lo que en realidad se hace en las aulas (Lomas, 2014: 12).

Esta coherencia e incoherencia mencionada por Lomas es visible cuando uno se pregunta ¿en qué consisten las ideas de educación que tiene cada actor involucrado en el proceso educativo? Es decir, ¿cuáles son las ideas acerca de la educación que tienen tanto los profesores como los alumnos? y ¿cuáles son las perspectivas a través de las cuales la institución, con todo su aparato, actúa? Pensar al acto educativo como una práctica que no escapa de las características impuestas por el sistema cultural, al cual pertenece, nos podría llevar a pensar de otra forma el porqué de la falla de implementación de estos enfoques en las aulas enmarcadas en contextos culturales que no son iguales a los que generan los enfoques de enseñanza que se quieren implementar por parte de las instituciones educativas.

Con la finalidad de hacer notar las diferencias en las nociones de enseñanza y aprendizaje que el sistema cultural impone, así como la necesidad de poner atención en dichos factores, durante el desarrollo de cualquier proyecto curricular, a continuación se aborda el caso de los profesores que laboran en el Instituto Confucio en la Universidad Nacional Autónoma de México (UNAM). 


\section{Diferencias culturales en las nociones de enseñanza y aprendizaje. El caso de los profesores del Instituto Confucio en la UNAM}

Como parte de una propuesta de un modelo que, a través de varios niveles, permite comprender la problemática que el Instituto Confucio enfrenta al diseñar sus planes y programas de estudio, se hace visible el hecho de que los profesores chinos no cuentan con la misma perspectiva, en cuanto a los conceptos de "enseñanza" y "aprendizaje" que tienen los profesores mexicanos, y no sólo eso, sino que dicha perspectiva tampoco es igual a la planteada por el saber disciplinar (García-Escalona, 2019).

Surgen, en las entrevistas realizadas en dicha propuesta, varios puntos al respecto que nos hacen saber que el pensar de los profesores chinos acerca de la educación en general y, específicamente, acerca de cómo enseñar y aprender lenguas, tiene características que divergen de las expuestas por las corrientes y teorías derivadas del saber disciplinar, mencionadas en la primera parte de este trabajo. Se presenta a continuación el fragmento de una entrevistai realizada a dos profesoras chinas, donde se expone la noción con la que ellas cuentan acerca del cómo enseñar una lengua, particularmente el chino:

\section{E: Entonces ¿cuál creen ustedes que sea el mejor método para enseñar chino?}

P4: Esta pregunta es muy dificil, hay un
montón de teorias
P5: "Estudiar meticulosamente y practicar
mucho"
E: Practicar mucho
P5: "Estudiar meticulosamente y practicar
mucho"; es decir, usar poco tiempo para
explicar y mucho tiempo para practicar
P4: Práctica
E: Practicar y practicar y practicar
P4: Yo también pienso eso
P5: ¿No?
P5: Sí, "Estudiar meticulosamente y
practicar mucho", sí
P4: Las teorías de las que hablas son
muchas, no son útiles
P5: Sí

P4: Porque si no practicas no tienes una retroalimentación

P5: Mj, además en México falta un contexto
de idioma, no hay muchos chinos con los
que puedas ir a practicar saliendo de clase

P4: Entonces, se debe practicar en clase

Se puede ver en este fragmento, que el método apropiado para enseñar lenguas, consistente en "estudiar meticulosamente y practicar mucho", no cruza por las propuestas disciplinares y no sólo eso, sino que, incluso, las profesoras chinas opinan que dichas teorías (constructivismo, psicolongüística y sociolingüística) son muchas y no sirven. No es que desconozcan tales ideas disciplinares, sino que la noción de enseñanza de las profesoras no tiene el mismo rumbo. Su idea acerca de cómo se debe enseñar obedece a otras lógicas procedentes de otro mundo social que hace que vean las nociones disciplinares como ajenas y no válidas; se trata de conocimientos habitualizados y que, como tales, son institucionalizados. Según Berger y Luckmann, el mundo institucionalizado aparece como objetivo, provocando que lo que se encuentre fuera de éste no lo esté:

Dado que dicho conocimiento se objetiva socialmente como tal, o sea, como un cuerpo de verdades válidas en general acerca de la realidad, cualquier desviación radical que se aparte del orden institucional aparece como una desviación de la realidad, y puede llamársela depravación moral, enfermedad mental, o ignorancia a secas (Berger y Luckmann, 2003: 87).

Es por esta razón que las profesoras no toman como válidas las propuestas provenientes del saber disciplinar: la forma en que ellas conciben la educación es la objetiva, pues es la que pertenece al mundo institucionalizado del cual ellas forman parte. Esta diferencia en los entendimientos no se reduce al concepto de enseñanza; los profesores chinos cuentan también con una concepción singular acerca del acto de "aprender" que, así mismo, difiere de lo planteado por los saberes disciplinares. El fragmento que se presenta a continuación, proveniente también del trabajo de tesis mencionado, pertenece a una entrevistail realizada a otra profesora china y expone un factor crucial acerca del verbo "aprender" en chino y de las implicaciones que el mismo lenguaje, en este caso, el chino, impone al acto de aprender; se trata de una divergencia que tiene que ver con rasgos propios del sistema cultural que se manifiestan en el lenguaje: 
E: Muy bien... ¿cómo crees que los estudiantes "estudian" chino? Es decir, cómo aprenden, porque la palabra "estudiar" también tiene el sentido de "aprender"

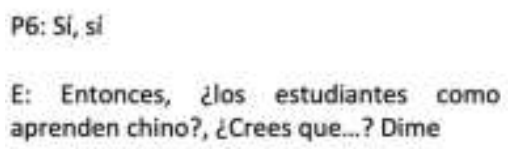

E: Traduce por favor jaja

P6: ¿Qué quiere decir esto? De hecho, aquil lo que dice es que estudiar y practicar ${ }^{9}$ no es lo mismo, estudiar es "esto es algo nuevo, lo voy a aprender"

E: Aja, acercarme a

P6: Ajá, acercarme al conocimiento o algo asi

E: Si

P6: Y practicar, es "ya sabes esto, ahora ya lo sabes, pero tienes que aprender a practicar, cómo usarlo, cómo practicarlo", entonces "estudiar" son dos cosas

\section{E: Entiendo}

P6: Aunque digamos que "学习" se traduce como "estudiar, aprender", de hecho, tiene dos sentidos

E: Si, si, si

P6: No sólo es estudiar, sino que también es practicar, entonces la actitud que se debe tener al estudiar un idioma, no puedes decir, como los alumnos cuando estudian, dices... por ejemplo, dices una palabra... dices... "amar"

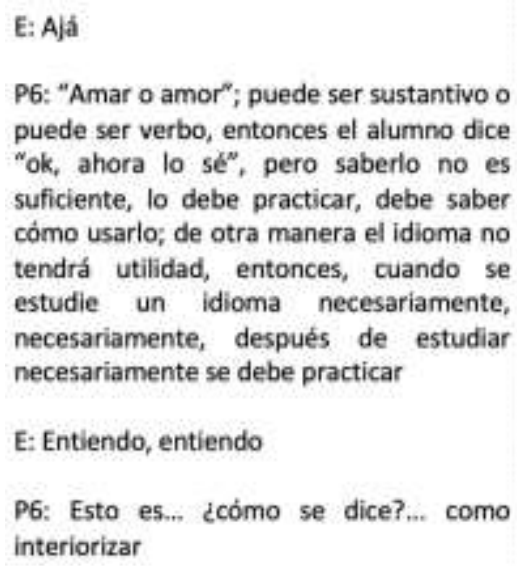

P6: "Amar o amor"; puede ser sustantivo o puede ser verbo, entonces el alumno dice "ok, ahora lo $s e^{n}$, pero saberlo no es suficiente, lo debe practicar, debe saber cómo usarlo; de otra manera el idioma no tendrá utilidad, entonces, cuando se estudie un idioma necesariamente, necesariamente, después de estudiar necesariamente se debe practicar

E: Entiendo, entiendo

P6: Esto es... ¿cómo se dice?... como interiorizar

El verbo "aprender" en chino consta de dos caracteres: 学习[xué] y [xí] . El primero de ellos significa "estudiar" o "aprender", mientras que, el segundo tiene el sentido de "practicar", "ejercitar", "repasar", "acostumbrarse a", "hábito", "costumbre", "práctica usual". De esta manera se puede observar que el verbo "aprender o estudiar" en chino implica, así mismo, un método: aprender y practicar.

Si observamos esta cualidad respecto a lo que contiene e implica el verbo "aprender" en chino veremos que el idioma chino ofrece por sí mismo una perspectiva acerca del acto de aprender. Se trata de una noción que aparece como parte del sentido común de la vida cotidiana y que posee la cualidad de real pues: "Como sistema de signos, el lenguaje posee la cualidad de objetividad. El lenguaje se me presenta como una facticidad externa a mí mismo y su efecto sobre mí es coercitivo. El lenguaje me obliga a adaptarme a sus pautas" (Berger y Luckmann, 2003: 85). De esta manera, el lenguaje se presenta como un primer estadío que inmediatamente organiza las experiencias y los conocimientos que se pueden adquirir: "El lenguaje también tipifica experiencias, permitiéndome incluirlas en categorías amplias en cuyos términos adquieren significado para mí y para mis semejantes" (Berger y Luckmann, 2003: 55). Esta manera de asimilar la realidad, determinada por el lenguaje, encamina de facto las perspectivas que se puedan tener acerca de los actos de enseñar y de aprender, guiándolas por un rumbo determinado que no necesariamente coincidirá con el que propone el saber disciplinar, ni tampoco con el que los profesores mexicanos tienen.

Esta diferencia de entender los actos de aprendizaje y de enseñanza, determinadas culturalmente, nos haría pensar en la imposibilidad de proponer a los profesores chinos que piensen dichos actos de acuerdo con los lineamientos disciplinares. El suponer que existe sólo una manera de entender el aprendizaje y la enseñanza de lenguas nos llevaría a posturas profesionales que tratan de imponer concepciones hegemónicas que no 
prestan atención a posturas diferentes. En palabras de Menendez:

Las interpretaciones dominantes tratan de reproducirse a través de prácticas profesionales y científicas, así como de las fuerzas sociales; y en consecuencia será en el juego de fuerzas donde veamos cómo determinadas concepciones pasan a constituirse en hegemónicas más allá de su corrección científica y teórica (2002: 242).

Es necesario aceptar que existen diferencias de interpretaciones de la realidad que promueven propuestas teóricas y metodológicas válidas en sí con el fin no caer en actos de imposición de determinadas concepciones dominantes. La legitimación de concepciones diferentes al saber hegemónico permitiría crear propuestas teóricas y metodológicas diversas y que apunten a funcionar mejor. Es necesario, así, hacer caso de estas diferentes interpretaciones de la realidad y analizarlas en función de una red más amplia de relaciones de las cuales son parte: "sólo podremos comprender los principios que rigen la interpretación y elaboración de los significados en la medida en que sean capaces de especificar la estructura y coherencia de los contextos más amplios en que se crean y transmiten significados específicos" (Bruner, 1991: 79).

\section{Relaciones y configuraciones en el aula de lenguas}

Como se mencionó en la sección anterior, existen nociones diferentes, determinadas culturalmente, acerca de los actos de enseñar y aprender, lo cual da una pauta para pensar que las propuestas disciplinares de educación lingüística, es decir, las ideas generadas por las corrientes mencionadas en el primer apartado de este trabajo, no siempre van a ser entendidas, ni mucho menos aplicadas, como se espera por parte de los docentes, pues como se pudo apreciar, las nociones llevar una construcción cultural que difícilmente tendrá la misma significación en contextos diversos.

En esta sección se presentan otros factores que rodean al acto de educación lingüística y que lo vuelve aún más complejo. Se trata de factores presentes en las relaciones que se entablan entre los diferentes actores involucrados en el acto educativo y que harán que dicho acto se configure de diversas maneras.

En el aula confluyen todo el tiempo diferentes discursos que provienen de diferentes espacios de significación. En el caso del aula de idiomas los discursos son aún más diversos, puesto que no son sólo lo que se pretende enseñar pertenece a un sistema cultural ajeno, sino que el mismo agente que busca introducir dicho sistema cultural puede, así mismo, provenir de éste, haciendo que los procesos de comunicación se vuelven más complejos.
Con el fin de visibilizar algunos de los discursos provenientes de los docentes de lenguas, se analizarán algunos puntos que surgen en los fragmentos que se muestran a continuación, los cuales provienen de dos entrevistas iii realizadas a tres profesores chinos. En dichos fragmentos, los profesores mencionan las cualidades que ellos observan entre los métodos de enseñanza "chinos" y "extranjeros", así como la viabilidad de su uso, dependiendo del tipo de estudiante con el que se trabaje:

Entrevista Persona 6

P6: Yo pienso que deben ir juntos... aparte, lo más importante es, lo más importante es, yo creo que se debe ver a quienes se les enseña

\section{E: Muy bien}

P6: Es decir, las caracteristicas de tus estudiantes; debes de decidir cómo formular de acuerdo con las caracteristicas de tus estudiantes, es decir, formular una manera o una manera de enseñanza que les adecúe

E: Si, muy cierto, muy cierto

P6: Entonces, yo creo que no es simplemente decir: "ocupo este" y asi todos los dias, no... porque, por ejemplo, llevo más de seis años enseñando chino en México, y los muchos alumnos que he tenido estudian porque les interesa, no porque quieran ser sinólogos

\section{E: Sí}

P6: Sinólogos, no quieren ser eso; lo que ellos quieren es conocer la cultura china, desean que la clase sea muy interesante

\section{E: Si, muy cierto}

P6: No les gusta practicar y practicar y practicar... practicar así esta manera de practicar de hecho en las licenciaturas en China, en este tipo de educaciòn, si se estudia un idioma extranjero, probablemente sea que los chinos 10 enseñen asi, hacemos ejercicios sin parar, sin parar, $\sin$ parar... incluso puede que haya enunciados que nunca vas a ocupar en la vida real

\section{E: SI, es verdad}

P6: Pero se hace esto porque se piensa que debes entender cómo es este enunciado, cómo es su estructura

E: Si 
P6: Si, entonces es por eso... entonces yo creo que debemos ver cuáles son las caracteristicas de los estudiantes, desde luego que todo lo que dijiste en el segundo punto, es decir, que hay que comprender el proceso cognitivo, cómo obtienen el conocimiento

Entrevista Personas 9, 10

\begin{abstract}
P10: Además, pero, además, pero, otra cosa es que, por ejemplo, si es la universidad, por ejemplo, si su carrera es el chino o traducción, entonces las estructuras son muy importantes, es decir, por supuesto que se deben de asegurar que los enunciados que pronuncian son muy correctos, porque ese es su trabajo, entonces no necesitan de juegos, no necesitan juegos, sollo es hacer que practiquen, practiquen, practiquen, $y$ que hablen y hablen $y$ hablen

P9: $Y$ pronunciar y pronunciar y pronunciar

P10: Pronunciar y pronunciar y pronunciar, eso es lo mejor, porque ellos no necesitan

juegos, porque es una carrera, "si no estudias vuelve a casa por favor"

E: Entonces, lo más importante es ver cómo son los alumnos, ver cuál es el objetivo

P10: Si, ver cual es el objetivo de los alumnos, si, por ejemplo, los niగios o..

P9: Son juegos

P10: Juegos, no es lo mismo, ver la edad de los alumnos, el objetivo de los alumnos, por qué estudian chino, sì es que estudian chino por interés, entonces juega con ellos, si estudian chino por trabajo, para ser traductores, entonces haz que practiquen $y$ practiquen y practiquen $y$ que hablen $y$ hablen y hablen

P9: Entonces, en el chino hay que ver quièn es el otro, si son niños, si son adultos o personas que se especialicen en trabajo de traducción
\end{abstract}

Se observa que la diferencia en el "hacer" que plantean los profesores chinos no está relacionada con las diversas maneras en que se plantean en Occidente, es decir, la diferencia entre métodos que los profesores chinos plantean no estriba en si el método es, por ejemplo, estructural o comunicativo. La lente que ellos ocupan para ubicar las diferentes maneras del "hacer" no es la misma que la empleada por el saber disciplinar; la diferencia parte, más bien, de lo que ellos tienen como conocimiento objetivado, es decir, el "cómo se hace" en China.

Además de este conocimiento referente al "cómo hacer", existe en los profesores chinos una imagen acerca de los roles tanto del alumno como del profesor y de lo que cada uno debería ser capaz de hacer que les permite ver diferencias en las maneras de proceder de alumnos y maestros chinos y mexicanos:

...toda transmisión requiere cierta clase de aparato social, vale decir que algunos tipos se identifican como transmisores y otros como receptores del "conocimiento" tradicional, cuyo carácter específico variará, por supuesto, de una sociedad a otra (Berger y Luckmann, 2003: 92).

Las maneras de comportarse del transmisor y el receptor están perfectamente ubicadas y tipificadas por los profesores chinos, permitiéndoles observar diferencias con el "hacer" de los mexicanos y de deducir que no sólo se trata de aplicar métodos "chinos" o "no chinos", sino de observar si los que los ejecutan están capacitados para ello o no, pues como mencionan también Berger y Luckman:

Los orígenes de cualquier orden institucional se encuentran en las tipificaciones de los quehaceres propios y de los otros, lo que implica que los objetivos específicos y las fases entremezcladas de realización se comparten con otros y, además, que no sólo las acciones específicas, sino también las formas de acción se tipifican (2003: 97).

Los profesores chinos ubican diferentes maneras de "hacer", de acuerdo con los tipos de estudiantes: exponen, por un lado, al "método de enseñanza chino", consistente como se mencionó, en "enseñar poco y practicar mucho", como el que verdaderamente sirve cuando el estudio es serio, es decir, cuando los estudiantes "verdaderamente" quieren aprender chino para llegar a ser sinólogosiv o traductores; se trata de un método que implica una gran disciplina y compromiso por parte del estudiante y que "verdaderamente" da resultados. Además, exponen el "otro" tipo de métodos, caracterizados por ser "juegos" y cuyo uso es apropiado cuando a los alumnos sólo les interesa conocer y disfrutar, la cual es justo la percepción que los profesores chinos tienen de los alumnos que acuden al Instituto Confucio.

Un punto necesario de señalar es el de la distorsión de la que pueden ser objeto los conceptos en sus procesos de transmisión, debido a las diferentes maneras en que los sistemas culturales permiten a las personas acercarse a la realidad. En la entrevista se hace uso de la palabra "juegos" para aludir al otro tipo de métodos que se utiliza cuando el estudio no es "serio": aunque es posible que con ello se refieran a los métodos de enseñanza de lenguas provenientes del saber disciplinar, como el comunicativo, pues opinan que dichos métodos son aplicables aquí, pero no en China, este aspecto no está del todo expuesto en la entrevista. No obstante, este punto nos podría llevar a pensar en la distorsión que los conceptos pueden sufrir al ser transportados entre diferentes espacios semióticos y a 
tener en cuenta, tal como Menéndez recuerda a Bourdieu:

...la necesidad de una constante actitud de vigilancia epistemológica, pero no para conservar la originalidad del concepto, sino para observar las derivaciones paradójicas y hasta contradictorias desarrolladas en la práctica (Menéndez, 2002: 291).

Con este planteamiento, no se pretende que los conceptos queden intactos, a través de las diversas transmisiones entre diferentes espacios y los diferentes agentes, sino de observar de qué manera fluyen los conceptos a través de su transmisión y de qué manera los sujetos se apropian en sus prácticas:

Todo concepto es provisional, lo cual podemos observar a través de la historicidad de los mismos. $Y$ por lo tanto, todo concepto se define realmente en sus usos más allá de las acuñaciones originarias, lo cual no niega el papel de éstas, sino que las remite a los sujetos y fuerzas que se hacen cargo de los conceptos, teorías y prácticas (Menéndez, 2002: 295).

De nuevo, esto nos lleva a pensar en la imposibilidad de que los conceptos sean aplicados de la misma manera en que se emiten desde el saber disciplinar y en los fracasos que conllevaría promover la implantación de dichos conceptos en prácticas que obedecen a conocimientos y entendimientos procedentes de espacios semióticos diferentes.

Existen nociones acerca de la diferencia de los métodos de enseñanza "propios" y "ajenos"; se reconoce por parte de los profesores chinos un método propio, válido y efectivo, si se cumplen ciertas circunstancias, las cuáles son, en realidad, que el alumno logre comportarse de la manera en que un alumno chino lo haría y, por otro lado, los métodos ajenos, válidos y efectivos cuando los alumnos se comportan de la manera en que los alumnos mexicanos lo harían. Esto da otra perspectiva acerca de la factibilidad del empleo de métodos provenientes del saber disciplinar. Existen factores más allá de las nociones acerca de enseñanza y aprendizaje que hacen que determinada manera de "hacer" presente una coherencia o no. Los profesores chinos reconocen estos saberes disciplinares, pero también reconocen que su implementación depende del contexto en el que quiera ser utilizado.

\section{Función docente y métodos de enseñanza como traductor-filtro de espacios semióticos}

Lotman emplea el concepto de "frontera semiótica" para hacer alusión al carácter delimitado de la semiosfera respecto del espacio extrasemiótico o alosemiótico que la rodea y lo define como "la suma de los traductores'filtros' bilingües pasando a través de los cuales un texto se traduce a otro lenguaje (o lenguajes) que se hallan fuera de la semiosfera dada" (Lotman, 1996: 12).
Es mi intención, hacer uso de este concepto -frontera semiótica- para analizar lo que sucede con los actos de aprender y enseñar lenguas en el aula y la interacción dada entre alumnos y profesor. Se encuentra que el aprendizaje de una lengua no puede ir desprovisto del conocimiento del sistema cultural del cual proviene, lo que implica la necesidad, no sólo de poner atención en los diversos elementos culturales y de significación de los cuales el lenguaje se desprende, sino también en las diferentes concepciones que existen en los mismos actos de enseñar y aprender, tanto por parte de los profesores como por parte de los alumnos, y de los roles que ellos, como parte de estas concepciones establecidas, se espera que cumplan.

Haciendo alusión al concepto de "frontera semiótica", acuñado por Lotman, podemos abordar la labor del docente de lenguas como una función fronteriza [transfronteriza, transversal, o transdisciplinar], pues éste, con todos los métodos de los cuales puede hacer uso para llevar a cabo su labor, representa este filtro que traduce lo proveniente de un espacio semiótico dado, al espacio semiótico de los alumnos. El docente, al manejarse entre ambos espacios, hace asequible el espacio semiótico, relacionado con la lengua meta, al espacio semiótico del cual el alumno proviene, es decir, es capaz de traducir los elementos del espacio semiótico de la segunda lengua a los elementos del "primer" espacio semiótico, ya que éste, por su "carácter cerrado", no puede estar en contacto con elementos que se encuentran fuera de él:

El "carácter cerrado" de la semiosfera se manifiesta en que ésta no puede estar en contacto con los textos alosemióticos o con los no-textos. Para que éstos adquieran realidad para ella, le es indispensable traducirlos a uno de los lenguajes de su espacio interno o semiotizar los hechos no semióticos (Lotman, 1996: 12).

Tomar en cuenta la función de "frontera semiótica", que, como traductores-filtros-bilingües que permiten el intercambio de información entre diferentes espacios semióticos, llevan a cabo los profesores de lengua y sus métodos de enseñanza, permitiría ver desde otra perspectiva el problema de la factibilidad de determinado método, o bien, la necesidad de hablar de métodos propios de acuerdo con cada situación en el aula, pues, si decimos que en el aula de idiomas interactúan los diferentes espacios semióticos a los que pertenecen los profesores, los alumnos y el objeto de estudio -que en ese caso es la lengua meta-, las dinámicas que se desarrollen serán diferentes en la medida en que los actores con sus espacios de significación cambien.

Así, los métodos de enseñanza no podrían ser separables de las prácticas que se llevan a cabo, pues es en la práctica donde se desenvuelve esta función dialógica del profesor-método. Es decir, es en la 
práctica donde confluyen todos los discursos de todos los actores, y es la práctica misma, la que crea los mecanismos de transmisión 0 condiciones de aprendizaje, que puedan ser asequibles o no para los actores: la práctica crea dichos mecanismos y éstos actúan para la misma.

Abordar los métodos de enseñanza de lengua, como un filtro-traductor bilingüe, que media entre ambos espacios semióticos permitiría abrir el panorama acerca de la necesidad de poner atención en los elementos que provienen de diferentes sistemas semióticos y hacer ver que el funcionamiento de los métodos de enseñanza depende del intercambio dialógico que los genera, así como de la nueva información que son capaces de promover:

La transmisión de información a través de esas fronteras, el juego entre diferentes estructuras y subestructuras, las ininterrumpidas 'irrupciones' semióticas orientadas de tal o cual estructura en un 'territorio' 'ajeno', determinan generaciones de sentido, el surgimiento de nueva información (Lotman, 1996:17). Lo que sucede en el aula de lenguas es una continua generación de sentido. El aprendizaje de una lengua implica acercarse a todo un aparato semiótico que facilita la comprensión e interpretación de objetos culturales y sociales. Los métodos de enseñanza de lenguas que toman en cuenta los diferentes espacios semióticos constituyen un mecanismo articulado que filtra información proveniente de todo un sistema cultural, de manera que lo que se enseña pueda ser codificado por el aprendiente.

Se trata, así, de un modo de codificación del espacio semiótico del cual proviene la lengua meta y que, hace necesario, así mismo, que se tomen en cuenta los elementos del espacio semiótico del aprendiente, pues "para una determinada semiosfera, esta realidad sólo deviene 'realidad para sí en la medida en que sea traducible al lenguaje de la misma" (Lotman, 1996: 14). De esta manera, el método de enseñanza es, en sí, un nuevo texto que, al codificar la información proveniente de otro sistema cultural y adaptarla al espacio del aprendiente con el fin de que éste logre comprender una realidad externa a la suya, permite la generación de diálogos.

Los métodos de enseñanza son, así, mecanismos de frontera que permiten la generación de textos nuevos. Para que estos nuevos textos sean producidos, menciona Lotman, que es necesario que exista un intercambio dialógico entre los partenaires, en el cual es indispensable que existan relaciones tanto de semejanza como de diferencia; se trata de un proceso continuo de transmisión y recepción en el que "el texto que ha sido transmitido y la respuesta a él que ha sido recibida deben formar, desde cierto tercer punto de vista, un texto único" (Lotman, 1996: 19). Todo este proceso se lleva a cabo en el aula de lenguas y los métodos de enseñanza son resultado, a la vez que, promotores del intercambio dialógico entre espacios semióticos.

El observar los métodos de enseñanza desde esta perspectiva permite apreciar, por un lado, que la aplicación de tal o cual método implica más factores que sólo los aparentes y que su funcionalidad no tiene que ver con la capacitación -o falta de ella-ofrecida a los profesores. Es necesario dar cuenta del aspecto cultural que acompaña invariablemente al acto educativo y, en el caso particular de la enseñanza de lenguas, el intercambio dialógico que se produce entre diferentes sistemas culturales.

Los problemas a los que se enfrenta la aplicación sorda de enfoques comunicativos de enseñanza, muy probablemente, tendrán que ver con estas diferencias en los entendimientos que los profesores tienen acerca de la enseñanza y del aprendizaje, así como de los factores que les acompañan.

Además de tener un papel impositivo, la importación de enfoques que no respetan los factores incluidos en los sistemas culturales en juego, también es probable que se convertirán en fracasos o simulaciones, puesto que institucionalmente se podrá decir que se aplican enfoques "de vanguardia científica", pero en realidad, en las aulas se hace otra cosa. Poner atención en los elementos que conforman los espacios semióticos a los que pertenecen, tanto los profesores como los alumnos, se vuelve un paso indispensable en toda creación curricular para la enseñanza de lengua:

Esas conclusiones, por supuesto, no niegan el valor y el papel de las teorías, explicaciones y/o productos producidos por la investigación o por la reflexión [...], sino que los refiere al juego de fuerzas sociales y académicas dentro del cual operan. $Y$ es en función de este proceso que proponemos que las teorías, ideologías, saberes sobre las razas, o sobre las etnicidades o sobre cualquier otra diferencia, deben ser observadas en las prácticas sociales a través de las cuales se realizan, dentro de las relaciones de hegemonía/subalternidad dominantes en cada contexto (Menéndez, 2002: 245).

Es necesario tomar en cuenta el espacio semiótico donde se desenvuelven, tanto el que enseña como el que aprende, así como el espacio del cual deriva el objeto de estudio. Poner atención en estos factores nos llevaría a pensar que no es lo mismo aprender chino en México que en Inglaterra o en China, ya que los mecanismos que se ponen en juego dentro del aula de lenguas no tienen que ver exclusivamente con la lengua, sino con todos los elementos semióticos que la generan.

Pensar a los profesores y a los métodos de enseñanza de lenguas como mecanismos traductores de diferentes 
espacios de significación, que promueven la generación de sentido, permitiría ampliar la brecha en la discusión acerca de la viabilidad de determinados métodos de enseñanza en el marco del campo del diseño curricular, contribuyendo, además, a fortalecer el fomento de un aprendizaje intercultural, el cual parte de la necesidad de "aceptar la presencia de los otros diversos, y aprender a construir opciones de futuro desde la alteridad diversa" (Universidad Nacional de Colombia, 2017: 7).

\section{Conclusiones}

La impartición de una clase de lenguas va mucho más allá que la mera enseñanza de una habilidad. Enseñar lenguas implica llevar a cabo un proceso muy complejo de traducción cultural, en el que la lengua es sólo una parte; se trata de una traducción cultural que va desde los métodos de enseñanza hasta las mismas maneras de ver la vida y de entender el mundo.

La competencia del docente de lenguas va más allá de enseñar una lengua: tiene que ver, también, con la integración de elementos provenientes de otros espacios semióticos, de los cuales los alumnos son parte. La labor del docente de lenguas contribuye, así, a la comprensión que, como sociedad, podemos tener de culturas que no son iguales a las nuestras, contribuyendo, de esta manera, en el establecimiento de un diálogo cultural.

Se observa que los saberes docentes -conocimiento que ellos tienen sobre la enseñanza y que desarrollan durante el ejercicio cotidiano de la docencia (Mercado, 2002), de manera particular en los profesores chinos, resultan, de muchas maneras, distintos a los del saber disciplinar. Si bien es cierto que los saberes docentes son diferentes entre maestros provenientes de la misma cultura, pues éstos no comparten los mismos espacios sociales ni los mismos momentos históricos, también lo es que las diferencias se acrecientan si hablamos de los saberes docentes de profesores provenientes de otras culturas.

Considerar al hecho educativo como un objeto abierto e inmerso en toda una red de significados propios de cada sistema cultural, permite observar que la adopción de ciertos lineamientos acerca de cómo enseñar lenguas es un acto más complejo de lo que a simple vista parece, y que muy posiblemente no sean factores burocráticos ni falta de capacitación lo que no ha permitido que los enfoques comunicativos de enseñanza de lenguas tengan el impacto prometido.

Entender la cultura como un espacio en el que navegan diversas prácticas semiótico-discursivas empleadas por los sujetos, permite observar al fenómeno educativo como una de estas tantas prácticas que posibilitan el flujo de significados y comunicación y que, por lo tanto, hacen necesario el uso de un análisis complejo, sistémico e inter y transdisciplinario.

Tener en cuenta que existen saberes docentes particulares, enmarcados completamente por la cultura a la que pertenece cada profesor, permite ver que el ejercicio docente va más allá del cumplimiento, más o menos puntual, por parte de los maestros, de prescripciones pedagógicas y curriculares.

Es necesario conocer en qué consisten las ideas que los actores tienen acerca de la educación, pues éstas, surgidas de un sistema cultural, determinarán los métodos de enseñanza que el profesor pueda emplear. De la misma manera en que es necesario considerar los saberes docentes respecto a los actos de enseñar y aprender, lo es tomar en cuenta las características del alumnado; cuáles son sus ideas respecto a dichos actos y de qué manera se construyen relaciones entre ambas partes.

Estos aspectos culturales nos hacen ver que es prácticamente imposible que se entienda la educación y los actos de enseñar y de aprender de la misma manera de forma universal. Atender la relación existente entre los métodos de enseñanza y de aprendizaje y el sistema cultural del cual provienen, puede ayudar a entender que éstos no son trasladables de sistema a sistema y que su producción derivaría, más bien, de un proceso de traducción y diálogo cultural.

El papel del profesor de lenguas es singular, ya que cuenta, por un lado, con toda una carga cultural que le hace entender de determinada manera la educación y los actos de aprender y de enseñar y, por otro, un bagaje disciplinar impuesto, que le obliga a actuar de acuerdo con los lineamientos institucionales, es decir, con planteamientos adoptados por la institución derivados de ideas hegemónicas disciplinares, como las expuestas al comienzo de este trabajo. Y no sólo eso, sino que al enseñar una lengua, no se puede escapar de la cultura en donde se inserta dicha lengua y, por lo tanto, ni de las nociones educativas que ese sistema cultural trae consigo.

Existe en la labor del docente de lenguas un constante y complejo proceso de traducción cultural que obliga a tomar, con más consciencia crítica, la adopción de cualquier enfoque de enseñanza. Conocer estos aspectos nos permitirá ser capaces de determinar propuestas que potencialicen los beneficios de las interacciones culturales y fortalezcan el campo de la Enseñanza de Lenguas.

El estudio de las características culturales presentes en un aula de lengua y de saberes no disciplinares acerca del "cómo hacer", pueden ofrecer herramientas que aborden la problemática de la falla en la aplicación de 
enfoques disciplinares en las aulas de enseñanza de idiomas.

No se puede pensar que las elaboraciones disciplinares acerca de cómo enseñar y cómo aprender son las únicas y las que se fundamentan en un saber verdadero. Es necesario escuchar las prácticas generadas desde otros sistemas culturales, de manera que se pueda "lograr que el mundo converja hacia un mayor entendimiento mutuo, hacia un mayor sentido de la responsabilidad y hacia una mayor solidaridad, sobre la base de la aceptación de nuestras diferencias espirituales y culturales" (Delors, 1996: 47).

El campo de la Enseñanza de Lenguas presenta grandes oportunidades para analizar y estudiar estos fenómenos, así como para comenzar a abrir caminos caracterizados por prácticas que den cuenta de identidades particulares y no hegemónicas.

\section{Referencias}

Berger, Peter L. \& Luckmann, Thomas (2003). La construcción social de la realidad. Buenos Aires: Amorrortu.

Bruner, Jerome (1991). Actos de significado. Más allá de la revolución cognitiva. Madrid: Alianza.

Delors, Jacques (1996). La educación encierra un tesoro. Informe a la UNESCO de la Comisión Internacional sobre la Educación para el siglo xxi. Paris: UNESCO.

García Escalona, Aurea Lilian (2019). Enseñanza del idioma chino en el Instituto Confucio en la UNAM: Un análisis de diferentes niveles de realidad para comprender el programa curricular. Tesis de Licenciatura. Ciudad de México: Universidad Nacional Autónoma de México.

Johnson, Keith (2008). Aprender y enseñar lenguas extranjeras. Una introducción. México: Fondo de Cultura Económica.

Littlewood, William (1996). La enseñanza comunicativa de idiomas. Introducción al enfoque comunicativo. Madrid: Cambridge University Press.

Lomas, Carlos (2014). La educación lingüística, entre el deseo y la realidad. Competencias comunicativas y enseñanza del lenguaje. México: FLACSO.

Lotman, Iuri M. (1996) La semiosfera I. Semiótica de la cultura y del texto. Madrid: Cátedra.

Menendez, Eduardo Luis (2002) La parte negada de la cultura. Relativismo, diferencias y racismo. Barcelona: Bellaterra.

Mercado, Ruth (2002) Los saberes docentes como construcción social. México: Fondo de Cultura Económica.

UNESCO (2010) (Organización de las Naciones Unidas para la Educación, la Ciencia y la Cultura). Invertir en la diversidad y el diálogo intercultural. París: UNESCO.

Universidad Nacional de Colombia (2017). Cátedra UNESCO-Diálogo Intercultural: "Competencias Interculturales: marco conceptual y operativo" en UNESDOC Biblioteca Digital [En línea]. Disponible en: https://unesdoc.unesco.org/ark:/48223/pf0000251592 [27 de septiembre de 2020]

\section{NOTAS}

\footnotetext{
${ }^{\mathrm{i}}$ La transcripción de esta entrevista puede ser localizada en el Anexo 3 de la tesis de García Escalona (2019), incluida en las referencias de este trabajo, con el título "Entrevista personas 4 y 5 ". La imagen que se presenta en este trabajo es un extracto de ésta.

${ }^{\text {ii }}$ La transcripción de esta entrevista puede ser localizada en el Anexo 3 de la tesis mencionada (García Escalona (2019), con el título "Entrevista persona 6". La imagen que se presenta en este trabajo es un extracto de ésta.

iii Las transcripciones de estas entrevistas pueden ser encontradas en el Anexo 3 (García Escalona, 2019), con los títulos "Entrevista persona 6" y "Entrevista personas 9 y 10 ". La imagen que se presenta en este trabajo es un extracto de éstas.

${ }^{\text {iv }}$ Los sinólogos son quienes estudian la lengua y/o la cultura china
} 